\title{
Development of Educational Platform for Experiments of Electric Machines
}

\author{
Yuan-Chieh Chin \\ Electrical Engineering, Chienkuo Technology University, Changhua 50094, Taiwan \\ Correspondence should be addressed to Yuan-Chieh Chin; cyc@cc.ctu.edu.tw
}

Received 25 February 2014; Accepted 29 March 2014; Published 22 April 2014

Academic Editor: Her-Terng Yau

Copyright (C) 2014 Yuan-Chieh Chin. This is an open access article distributed under the Creative Commons Attribution License, which permits unrestricted use, distribution, and reproduction in any medium, provided the original work is properly cited.

\begin{abstract}
An educational platform to improve the test and the evaluation of the experimental data in electric machine laboratory is developed. The system is complement to the course taught of electric machines to undergraduate students. The proposed system can automatically acquire the experimental data from data acquisition device on the personal computer and transfer the data through interface card to the host server. The host sever performs the essential calculations of the obtained parameters. After the students enter their computational value through system interface, the host server could record, compare, estimate, and chart the result in real time. The system not only improves the efficiency of the experimental data evaluation but also provides the online comments including experimental purposes, principles, necessary instrument equipment, special notes, operation procedures, and results recording.
\end{abstract}

\section{Introduction}

In 1988, Keyhani and Hao [1] proposed a microcomputeraided data acquisition system for laboratory testing of transformers and electrical machines. Their system focuses on the measurement of the characteristics of synchronous machine and transformer. The analysis software of Keyhani and Hao's system only aims at the synchronous motor $\mathrm{V}$ type characteristic curve and transformers open-circuit, short-circuit experiments. In 2000, Kasten [2] proposed an integrating computerized data acquisition and analysis system. Kasten's system provides the safe operations of instrumentations and measurement procedures over wide range of experimental tests. The data acquisition and subsequent analysis of Knastan's system is LabVIEW by National Instruments. In 2004, Sellschopp et al. [3] proposed an automated system for frequency response analysis with application to an undergraduate laboratory of electrical machines. Sellschopp and Arjona's system provides a LabVIEW-based automated system to carry out frequency response tests in electrical machines laboratory. An advantage of Sellschopp and Arjona's system is its friendly-user interface and avoiding the risky utilization of oscilloscopes in laboratory experiment. In
2006, Shuhui and Challoo [4] proposed a new approach that, by integrating computer-assisted teaching methodology in classroom presentation, substantially restructures the course, so that it provides a comprehensive treatment of electricdrive systems.

In the traditional electric machinery experimental systems of laboratory courses, the students have always to wait for a long time to get the instructor's comments after they submit their experimental results. Comparing with the above mentioned systems, propose an integrated online system, with client/server architecture, to improve the record, evaluation, and verification process of the experimental data in electric machine laboratory. The proposed system can automatically acquire the experimental data from data acquisition device on the personal computer and transfer the data through interface card to the host server. The host sever performs the essential calculations of the obtained parameters. After the students enter their computational value through system interface, the host server could record, compare, estimate, and chart the result in real time. The following lists the seven achievements of the system and the eight functions applied in the electric machinery experiments. 


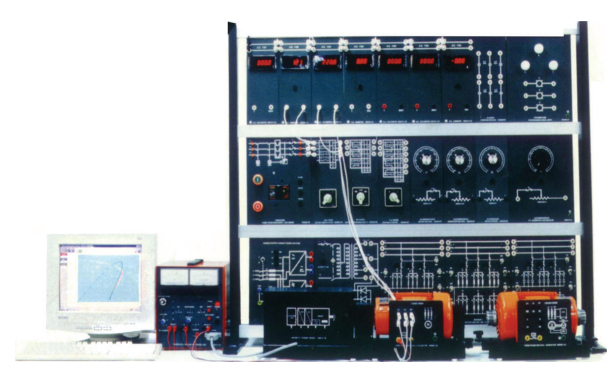

FIGURE 1: The practical instrument of one experimental set.

The seven achievements are

(1) innovative and powerful database interconnection technology with high feasibility,

(2) practical data acquisition technology,

(3) highly portable recording technology,

(4) novel characteristic drawing technology without the drawing orders,

(5) practical network database technology in production, office and study,

(6) innovative network data comparing and error automatic distinguishing technology,

(7) smart technology to automatically adjust the parameters of the network practice.

The eight functions of the online real-time electric machinery experimental system are

(1) automatic measurement: computer-based data acquisition interface;

(2) automatic recording: it is convenient and portable for students to save the data;

(3) characteristic curve drawing: users can draw the characteristic figures by setting some variables;

(4) online practice: the network system can verify the correctness automatically;

(5) online handover: the network system can identify if the homework is handed.

(6) online inquiring function for teachers: teachers can recognize students homework and examination results automatically;

(7) online library: it provides the online E-books for students to read and survey.

(8) online smart questioning system: it can adjust the difficulty of the examination and grade automatically.

In addition to the automatic measurement and recording functions, other education organizations without the automatic measuring interface can also use this system. They can use many functions, such as automatic saving, characteristic curve drawing, and online homework handover, by importing the experimental data obtained with the traditional wiring into this system.

\section{Laboratory Setup and System Architecture}

The main equipment of laboratory includes the traditional units as follows: transformers, DC machines, three-phase synchronous machines, single phase induction motors, threephase induction motors, and so forth. Additional equipment is por modules, digit meters, starters, synchronous lamps, load resistor banks, and field rheostats. In the proposed system, we must have the other equipment including voltage and current transducers, torque generator, and speed generator to combine with DAQ card and PC.

The laboratory experiment may consist of many experimental sets. The practical instrument of one experimental set can be seen in Figure 1. Each set equips transformer induction motor, synchronous machine, DC machine, signal conditioner, A/D converter, and PC with interface card. The overall view of the system architecture is shown in Figure 2 [5].

First, the system must calculate the measurement data grabbed at voltage signal and a current signal at an instant through the data acquisition card (PCL-818) [6]. Then, the various handwritten data can be record and save in Access database. Make use of the concert of the database and ASP to upload to the host server system. The host sever compares the automated computational data with the upload data, which was calculated by the student. The verification results reply to the client system immediately.

In the laboratory experiments, students have to assemble the circuit, connect the necessary instrument, make the measurements and essential computations, compare the data to the expected behavior, and input the computational data to PC. The initial experimental signal should be processed through signals conditioner and DAQ card (PCL-818), so that the converted experimental data can be transmitted to personal computer and keep a record in client PC. After that students input their computational data and submit both of the data, including recorded measuring data in database and inputted computational data, to host server via interface card. The integrated online system will compute the recorded measuring data automatically, so that the system could compare the automated computational data to another data, which are inputted and computed by students lately.

\section{Parameters Determining}

The equivalent circuits of electric machines are very useful tool for determining the electric machines' response to 


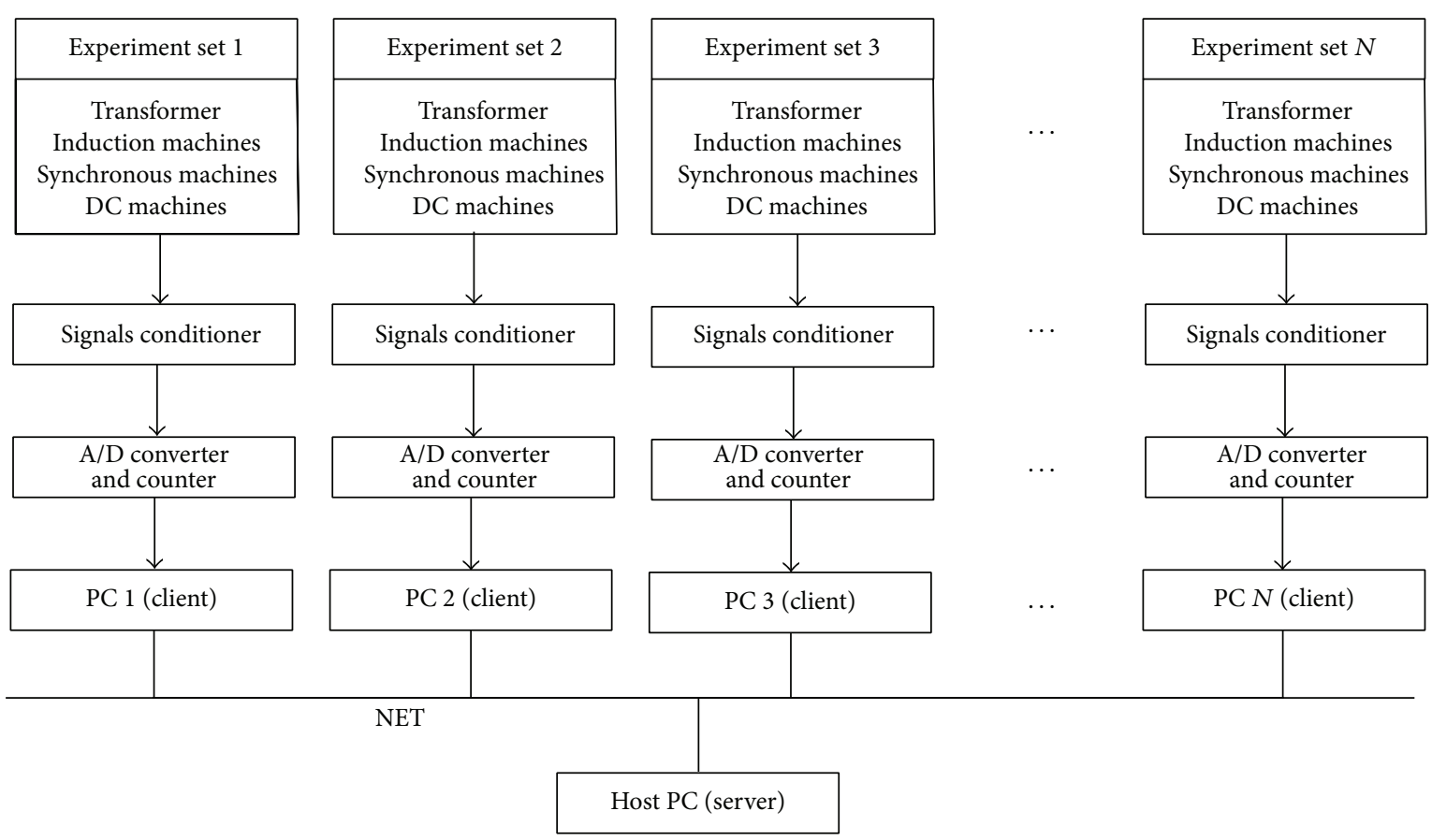

FIgURE 2: The overall view of system architecture.

changes in load. However, if a model is to be used for a real machine, it is necessary to what the elementary parameter values are that go into the model. How can the parameters be determined for a real electric machine? These pieces of information may be found by performing a series of tests on the electric machines.

For example, wanting to experimentally determine the values of the inductances and resistances in the transformer model shown in Figure 3, an adequate approximation of these values can be obtained with only two tests, the opencircuit test and the short-circuit test. The open-circuit test connections are shown in Figure 4. Full line voltage is applied to the primary of the transformer, and the input voltage, input current, and input por to the transformer are measured. The short-circuit test connections are shown in Figure 5. The input voltage is adjusted until the current in the shortcircuited windings is equal to its rated value.

From this information, the series equivalent elements $R_{\mathrm{eq}}$, $X_{\text {eq }}$ and the admittance of the excitation branch $R_{C}, X_{M}$ can be determined, as follows [7].

The magnitude of the excitation admittance can be found from the open-circuit test voltage and current

$$
\left|Y_{E}\right|=\frac{I_{\mathrm{OC}}}{V_{\mathrm{OC}}}
$$

The angle of the admittance can be found from knowledge of the circuit por factor. The open-circuit por factor $(\mathrm{PF})$ is given by

$$
\mathrm{PF}=\cos \theta=\frac{P_{\mathrm{OC}}}{V_{\mathrm{OC}} I_{\mathrm{OC}}}
$$

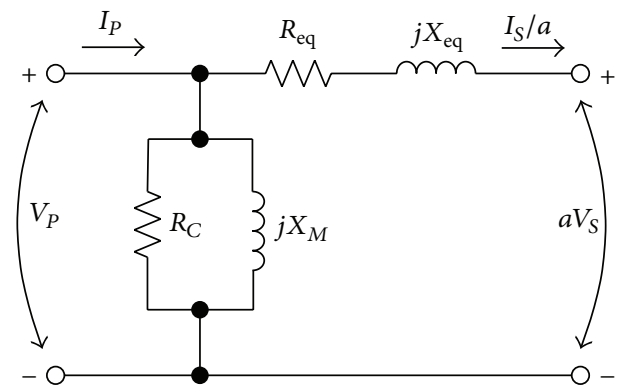

FIGURE 3: The approximation transformer model referred to the primary side.

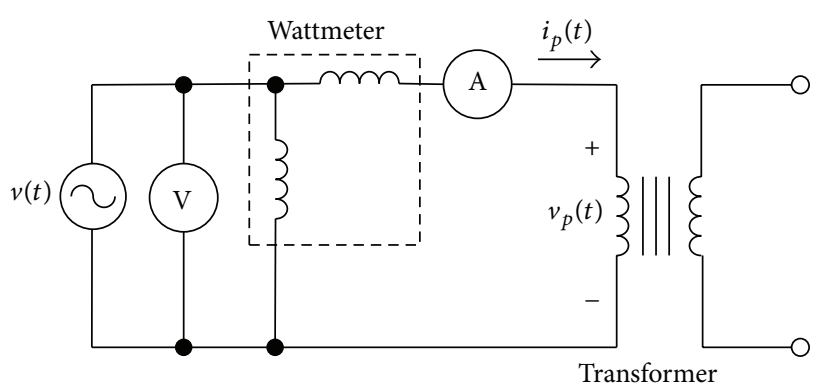

FIgURE 4: Connection for transformer open-circuit test.

and the por factor angle $\theta$ is given by

$$
\theta=\cos ^{-1} \frac{P_{\mathrm{OC}}}{V_{\mathrm{OC}} I_{\mathrm{OC}}} .
$$




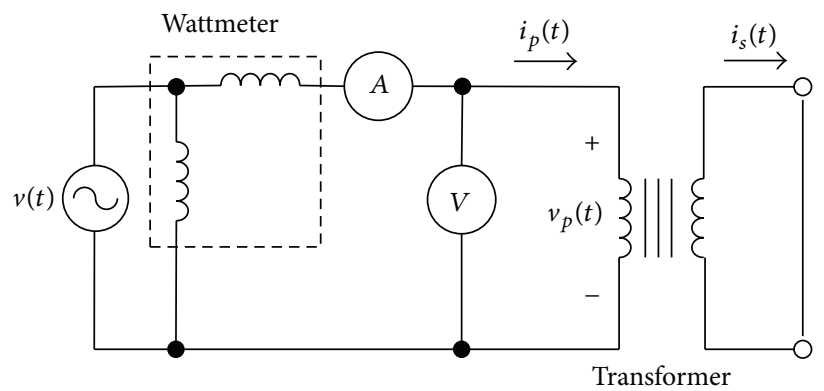

FIGURE 5: Connection for transformer short-circuit test.

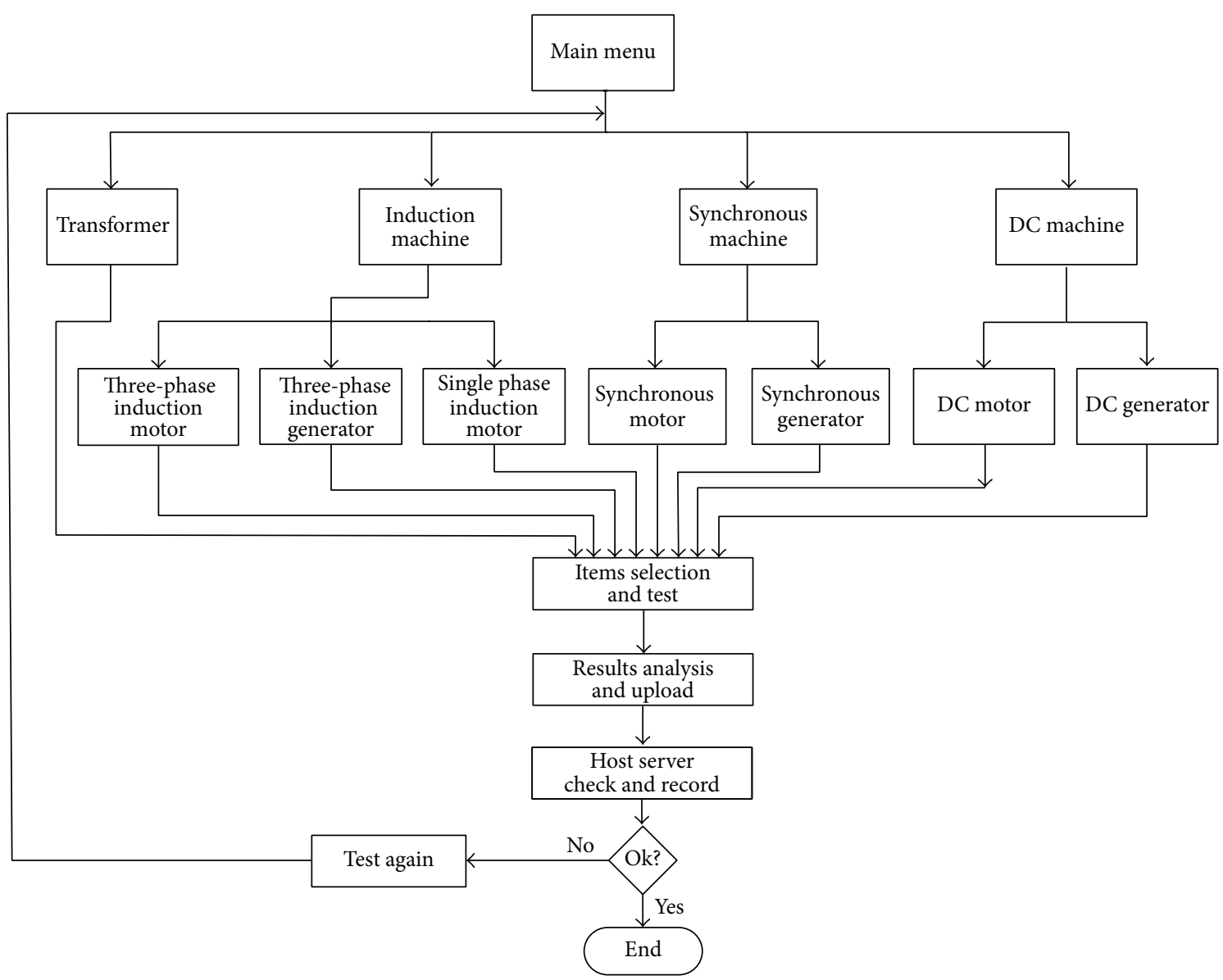

Figure 6: The overall view of the program modules and flow chart.

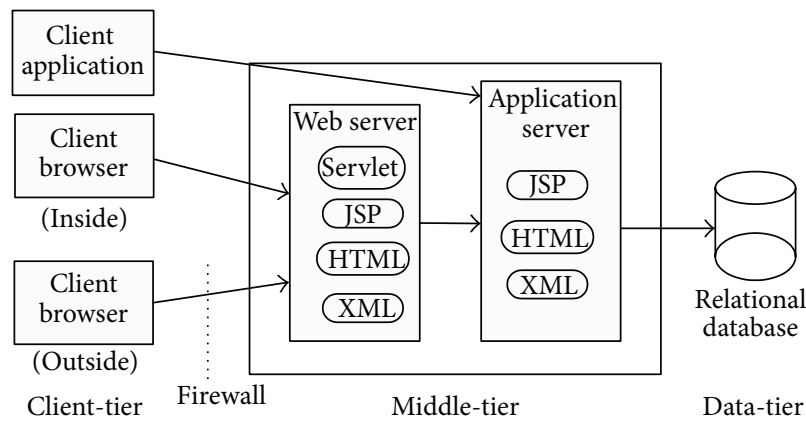

FIgURE 7: Multitier architecture. 


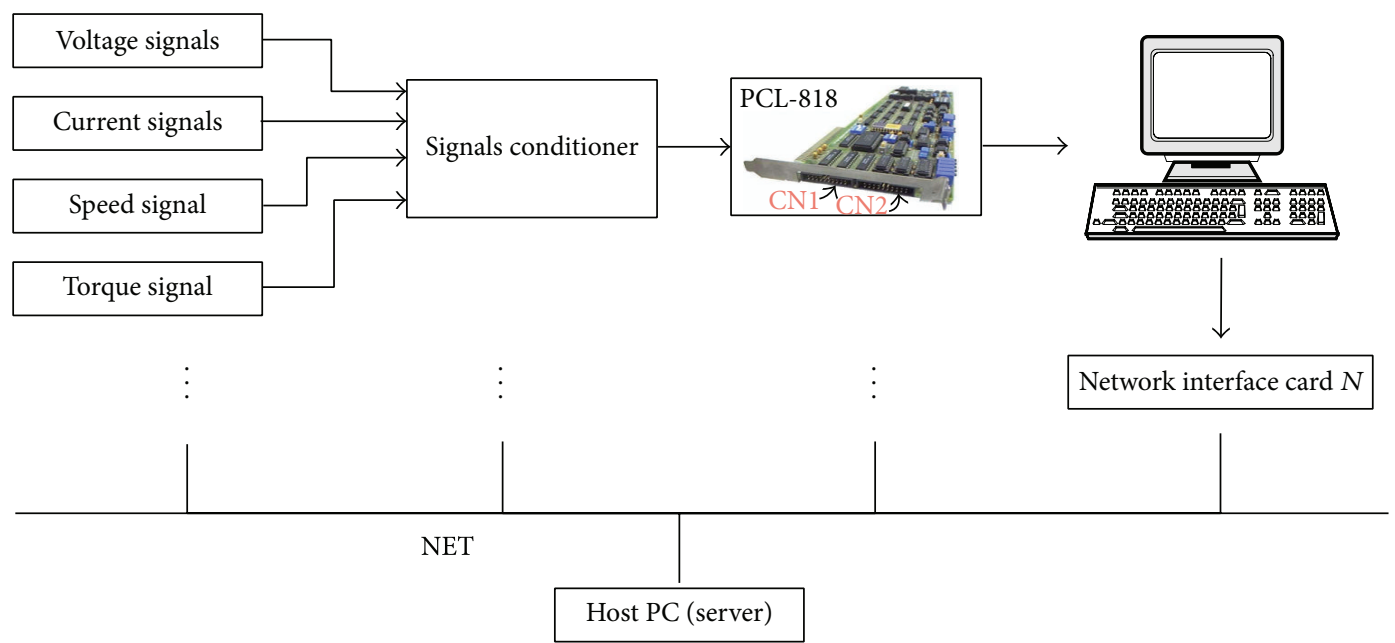

FIGURE 8: The processing flow of the experimental signals.

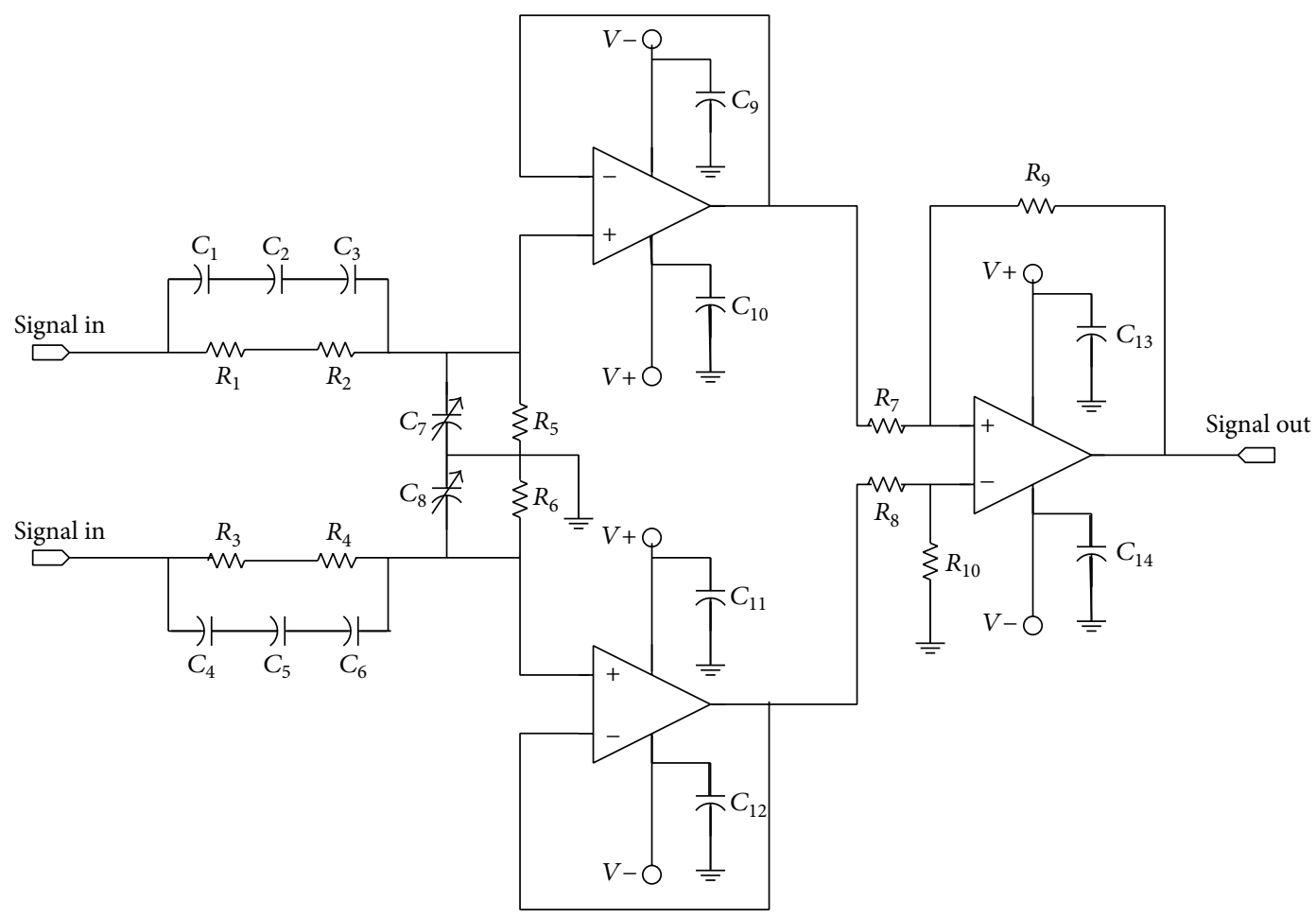

FIGURE 9: One channel voltage signal conditioner.

Therefore, the admittance $Y_{E}$ is

$$
\begin{aligned}
Y_{E} & =\frac{I_{\mathrm{OC}}}{V_{\mathrm{OC}}} \angle-\theta=\frac{I_{\mathrm{OC}}}{V_{\mathrm{OC}}} L-\cos ^{-1} \mathrm{PF}=G_{C}-j B_{M} \\
& =\frac{1}{R_{C}}-j \frac{1}{X_{M}},
\end{aligned}
$$

and the magnitude of the series impedance can be found from the short-circuit test voltage and current

$$
\left|Z_{\mathrm{SE}}\right|=\frac{V_{\mathrm{SC}}}{I_{\mathrm{SC}}}
$$

The por factor of current is given by

$$
\mathrm{PF}=\cos \theta=\frac{P_{\mathrm{SC}}}{V_{\mathrm{SC}} I_{\mathrm{SC}}},
$$

and the overall impedance angle $\theta$ is given by

$$
\theta=\cos ^{-1} \frac{P_{\mathrm{SC}}}{V_{\mathrm{SC}} I_{\mathrm{SC}}} \text {. }
$$

Therefore, the series impedance $Z_{\mathrm{SE}}$ is equal to

$$
Z_{\mathrm{SE}}=\frac{V_{\mathrm{SC}}}{I_{\mathrm{SC}}} \angle \theta=\frac{V_{\mathrm{SC}}}{I_{\mathrm{SC}}} \angle-\cos ^{-1} \mathrm{PF}=R_{\mathrm{eq}}+j X_{\mathrm{eq}} \text {. }
$$




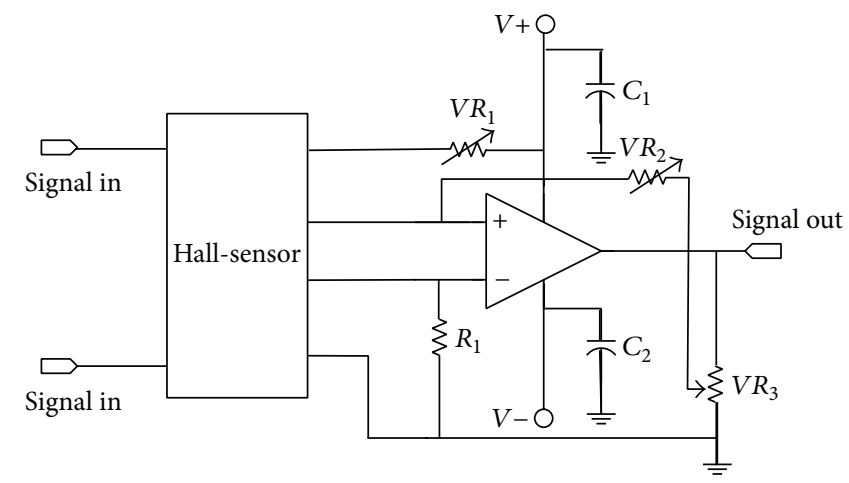

FIGURE 10: One channel current signal conditioner.

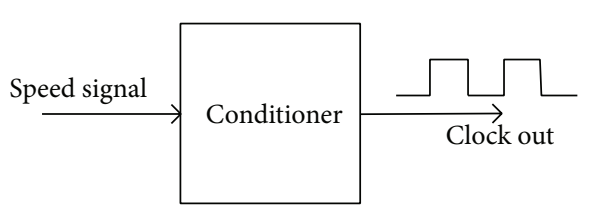

(a)

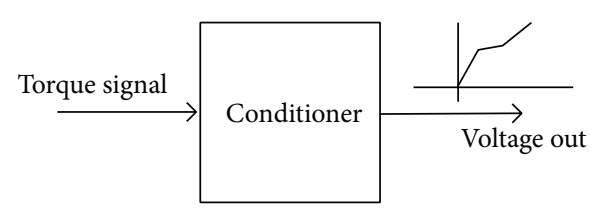

(b)

FIGURE 11: Speed signal conditioner and torque signal conditioner.

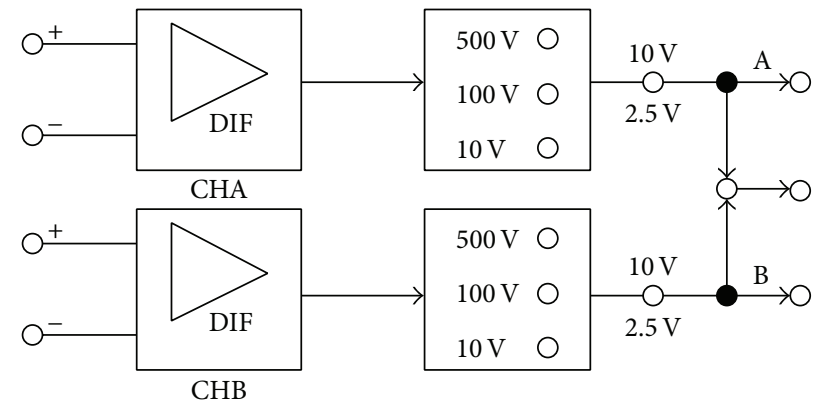

FIGURE 12: Voltage converter.

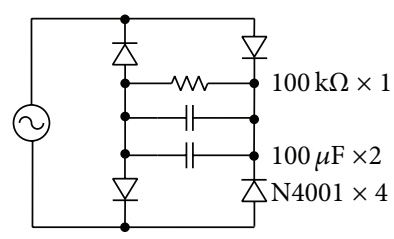

FIGURE 13: Rectifier.

The above-mentioned items, the input voltage, input current, and input por to the transformer can be measured manually by students and automatically by the system. If the measurement is performed in the automatic mode, all the por signals would be handled based on the rules of signal processing in the following, where $I$ is the effective value of line current, $V$ is the effective value of line voltage, $S_{i}$ is the input apparent por, $Q_{i}$ is the input reactive por, and $P_{i}$ is the input active por [8-10]:

$$
\begin{gathered}
I=\sqrt{\left(\frac{1}{n}\right) \sum_{i=1}^{n}\left(I_{i}\right)^{2},} \\
V=\sqrt{\left(\frac{1}{n}\right) \sum_{i=1}^{n}\left(V_{i}\right)^{2},} \\
S_{i}=\sqrt{3} V I, \\
Q_{i}=\sqrt{3} \frac{1}{n} \sum_{i=1}^{n}\left(V_{i}\right)\left(I_{i}\right), \\
P_{i}=\sqrt{\left(S_{i}\right)^{2}-\left(Q_{i}\right)^{2}} .
\end{gathered}
$$

From the above equations, the required quantities can be obtained through the calculation program designed with visual basic with the extracted voltage and current signals from data acquisition card.

\section{System Interface and Soft Architecture}

The system interface was designed on the basis of convenient use and friendly interaction between student and this system. The overall view of the program module and flow chart is shown in Figure 6. By using the system interface, it is very convenient to choose different kinds of experimental machine and the subunits' experiment can be proceeded subsequently. The system program can be divided into two parts: client system and host server system. The client system is written in visual basic and MS access and runs on top of 


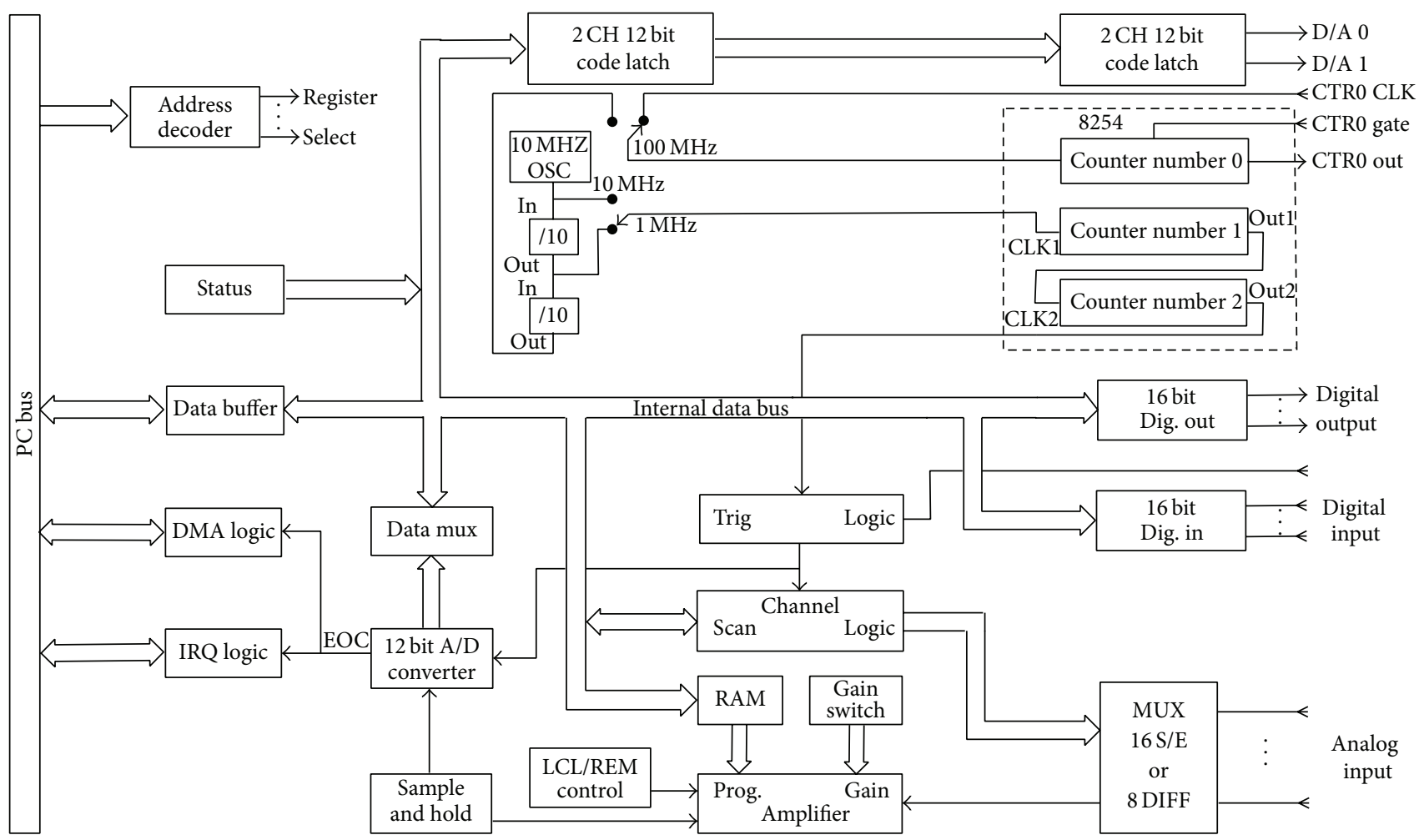

FIgURE 14: DAQ card (PCL-818).

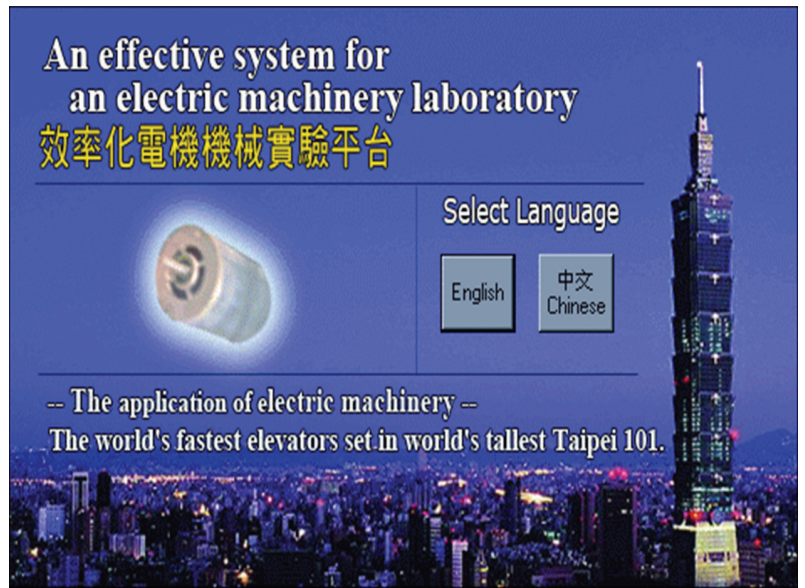

Figure 15: The title screen.

Windows XP Professional or Windows 7 Professional. The host server system is writing in HTML and active server page (ASP) and runs on top of Windows 7 Server. Both of the client and server computers have to connect to LAN or internet.

In this paper, the development environment includes VB and internet-based programs. Therefore, the whole structure of software can also be divided into VB and internet operation modes.

The internet-based program is mainly focused on the design and arrangement of online operation, where the functions of plot of characteristic curve, development of online

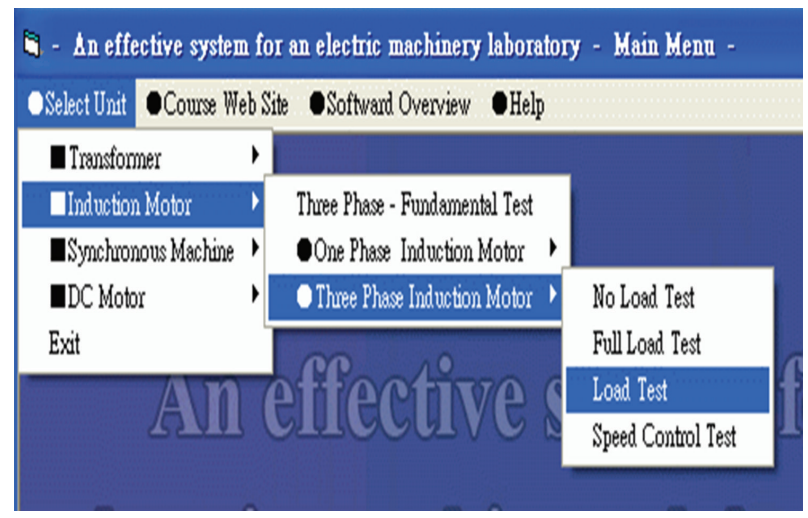

FIgURE 16: The pop-up menu appears.

platform for automatic data evaluation, online examination function for teachers, and online database are included.

N-tier application architecture provides a model by which developers can create flexible and reusable applications. By segregating an application into tiers, require the option of modifying or adding a specific layer, instead of reworking the entire application. A three-tier architecture is typically composed of a presentation tier, a business or data access tier, and a data tier. The current internet is mainly the bbased structure, which is three-tie architecture, followed by the collected mainframe and two-tier client/server. In the b development field, three-tier architecture is often used to 


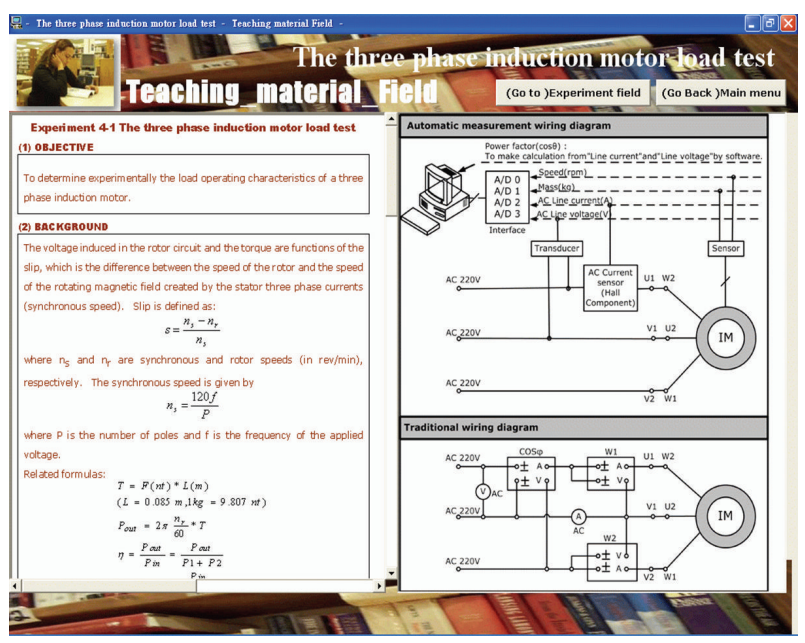

FIGURE 17: The subunit three-phase induction motor load test.

refer to websites, commonly electronic commerce websites, which are built using three tiers.

(1) A front end b server serving static content and potentially some cached dynamic content. In b-based application, front end is the content rendered by the browser. The content may be static or generated dynamically.

(2) A middle dynamic content processing and generation level application server, for example Ruby on Rails, Java EE, ASP.NET, PHP, ColdFusion, and Perl platform.

(3) A back-end database or data store, comprising both data sets and the database management system software that manages and provides access to the data.

In the three-tie architecture, the connection and coordination between servers would be more complicated than those in two-tie structure when dealing with a service. For the users in the client, the distributed processing can be conveniently completed with single internet connection and the uniform user interface of browser. Figure 7 is the typical three-tie application structure developed with JAVA [11, 12].

The three-tie structure includes client-tie for user interface, middle-tie for core application tools, and data-tie for data storage and processing. The middle-tie can be further divided into b-tie and application-tie. The application-tie is composed of Enterprise Java Beans (EJB) to deal with implementation of specific task. The user can be the one accessed from internet or EJB. And the b server is the gateway to access the system for user through the internet. This structure not only provides the distributed application environment, but also completes the cross-platform function. The firewall performs the encryption and verification.

Therefore, the teaching and experiment system in this paper is designed with Java Server Pages (JSP), which is a new dynamic webpage standard introduced by Sun Microsystems in June 1999. JSP is a b development technology based on Java Servlet and Java groups, which is an extension of Servlet 2.1
API. With this advanced technology, the dynamic website can be built with security and cross-platform functions.

The structure of JSP is similar to ASP. However, ASP is only applied in Windows NT/2000. On the other hand, JSP can be directly applied in most b servers without any modification to meet the idea of Java - "write once, run anywhere."

Java2 platform enterprise edition is a structure for enterprise applications developed by Sun. This structure has been supported by many software providers and has become the main product of enterprise application. JSP is a key component on the platform of J2EE. JSP and ASP both are based on the Web development technology for dynamic web pages. These two techniques can also provide software compiled function for designers and make the webpage separated logically. In addition, they both can provide more convenient and simpler development of website than CGI.

\section{Experimental Results}

The processing flow of the experimental signals is shown in Figure 8. The details of transducers in the signal block are described in Figures 9, 10, 11, 12, and 13. The DAQ card is shown in Figure 14.

When the student starts the client system, he/she can choose English or Chinese interface and the title screen is shown as in Figure 15. After the title screen, the pop-up menu will appear as shown in Figure 16. The student can choose experimental unit and subunit according to his/her experimental purpose in Figure 16. For example, a student chose the induction motor unit; then, he/she could get the subunit three-phase induction motor load test as shown in Figure 17. The screen in Figure 17 can be divided into three windows. The left window expresses the content of the experiment including purpose, principle, instrument equipment, special note, operation procedure, and result recording. The right upper window shows the automated measured experimental data. The right bottom window shows the wiring diagram of the chosen experiment. After the students select (click) the test button in Figure 17, the measurement model will be gotten as shown in Figures 18 and 19.

Another case is the three-phase synchronous motor vcurve test shown in Figures 16 and 21. They show nonload, $1 / 2$ full load, and full load V-curves and inverse V-curves of the three-phase synchronous motor.

As can be seen in Figures 18, 19, 20, and 21, the smaller left-up window of the screen shows the automated measured experimental data. The left-down window shows the curves according to what has been chosen which was described in the right bottom window (the differences between them as shown in Figure 18 to Figure 21). In the meantime, the experimental data is resaved as an access table, which includes the calculated value by student. The access file can be uploaded to the host server system through the b-based interface as shown in Figure 22.

The host sever compares the automated computational data with the upload data, which was calculated by the student. The verification results reply to the client system 


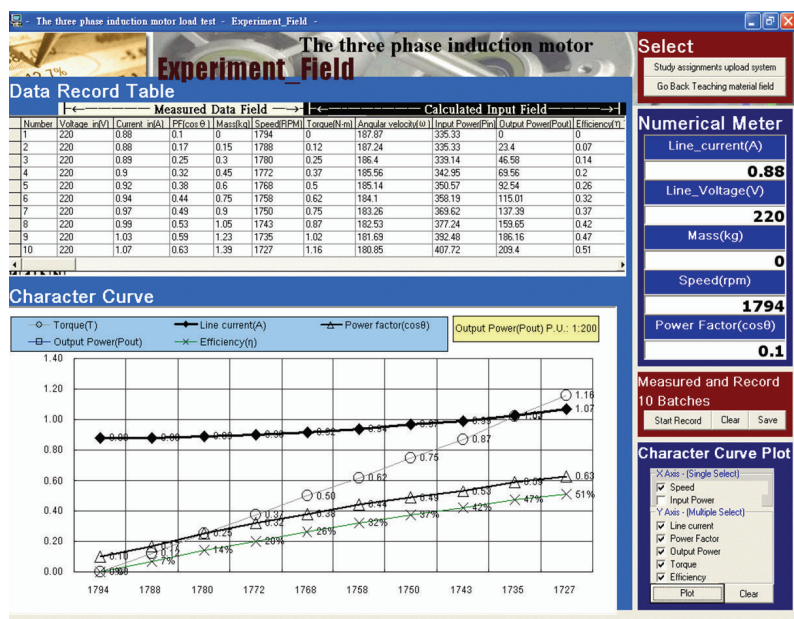

FIGURE 18: The measurement model 1 (speed versus current, por factor, torque, etc.).

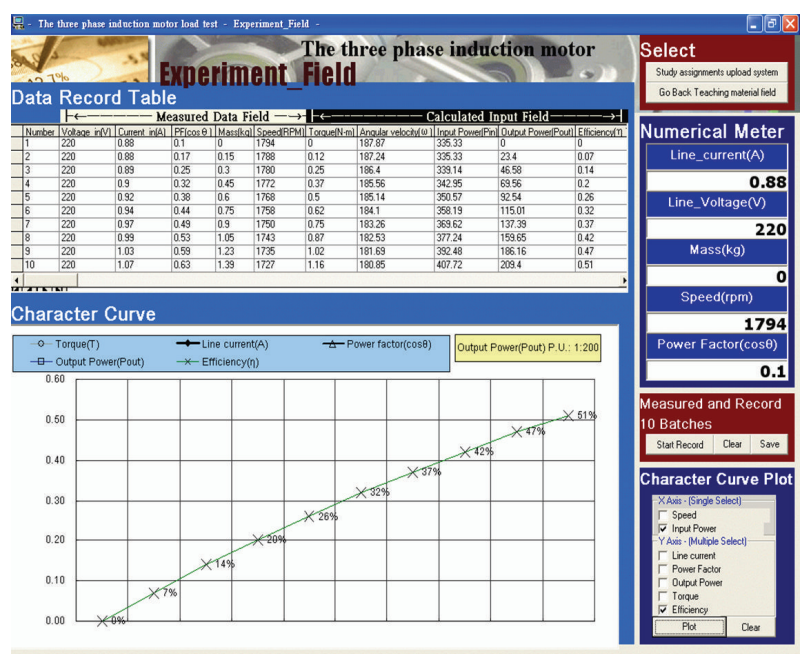

FIGURE 19: The measurement model 2 (por versus efficiency).

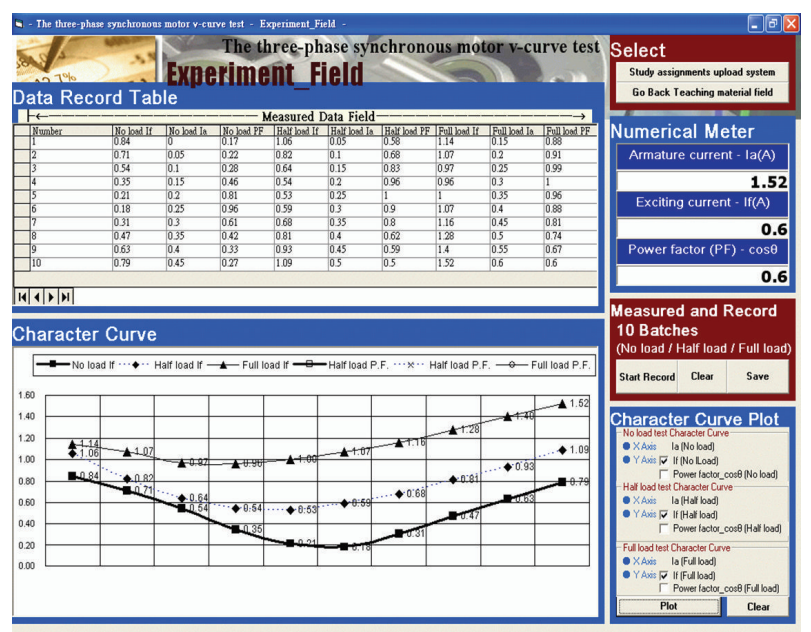

FIGURE 20: The V-curves (load current versus field current on the same graph to the same scale).

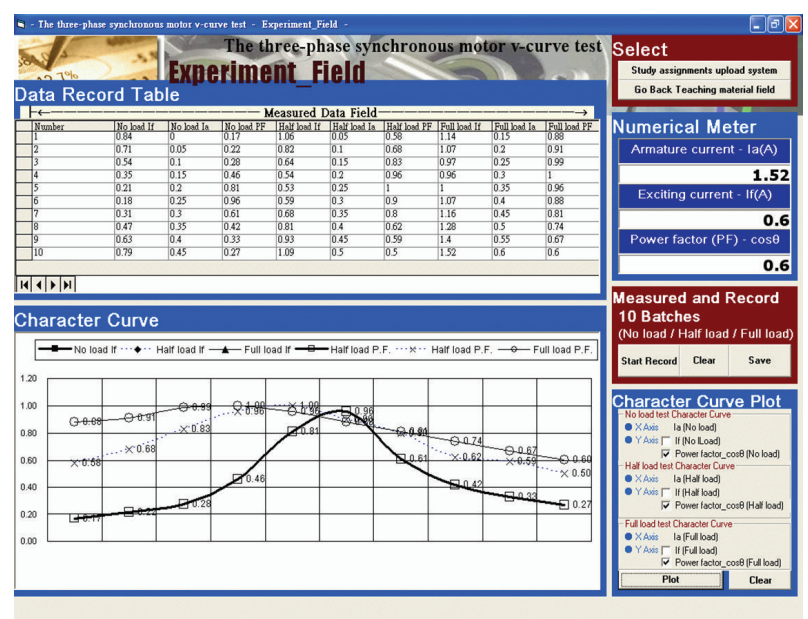

FIGURE 21: The inverse V-curves (por factor versus field current on the same graph to the same scale).

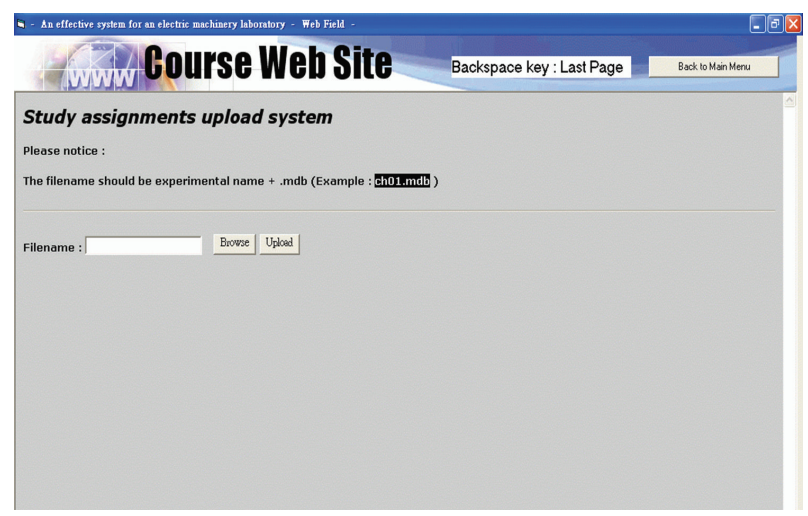

FIgURE 22: The b-base upload interface.

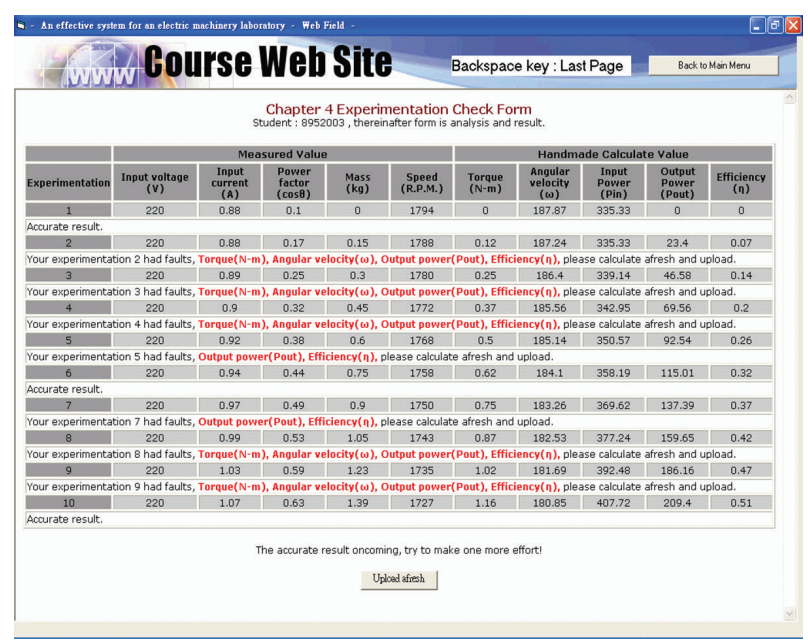

FIGURE 23: The experimental check screen.

immediately. The $\mathrm{b}$ screen showed the comparisons between the automated computation data and the calculated data. Figure 23 showed the experimental check screen. 


\section{Conclusions}

An educational platform for undergraduate student in electric machines is developed in this paper. The goal of the project is to provide a real-time system, which possesses automatic data acquisition, measurement, analysis, and realtime verification and instructional comment for experiment to electric machines laboratory. The advantages of this system make the student more familiar with theory and practice in specific content of electrical machines course. Besides, the instructor could efficiently and rapidly evaluate the student's experimental results and reply to the comment immediately.

\section{Conflict of Interests}

The author declares that there is no conflict of interests regarding the publication of this paper.

\section{References}

[1] A. Keyhani and S. Hao, "Microcomputer-aided data acquisition system for laboratory testing of transformers and electrical machines," IEEE Transactions on Power Systems, vol. 3, no. 3, pp. 1328-1334, 1988.

[2] D. G. Kasten, "Integrating computerized data acquisition and analysis into an undergraduate electric machines laboratory," in Proceedings of the 30th ASEE/IEEE Frontiers in Education Conference, pp. 13-17, Kansas City, Mo, USA, 2000.

[3] F. S. Sellschopp, A. Marco, and L. Arjona, "An automated system for frequency response analysis with application to an undergraduate laboratory of electrical machines," IEEE Transactions on Education, vol. 47, no. 1, pp. 57-64, 2004.

[4] L. Shuhui and R. Challoo, "Restructuring an electric machinery course with an integrative approach and computer-assisted teaching methodology," IEEE Transactions on Education, vol. 49, no. 1, pp. 16-28, 2006.

[5] Y. C. Chin, "The computer-aided system for electric machinery lab," in Proceedings of the UICEE Annual Conference on Engineering Education, pp. 183-185, Queensland, Australia, 2003.

[6] Advantech Data Acquisition Card (PCL-818), Advantech Co., 2007.

[7] S. J. Chapman, Electric Machinery Fundamental, McGraw-Hill, 5nd edition, 2010.

[8] "IEEE standard definitions for the measurement of electric power quantities under sinusoidal, nonsinusoidal, balanced or unbalanced conditions," IEEE Std. 1459-2010, IEEE Standard, 2010.

[9] "Electromagnetic Compatibility (EMC) - Part 4-30: Testing and Measurement Techniques-Power Quality Measurement Methods," IEC Std. 61000-4-30, 2008.

[10] M. H. J. Bollen and I. Y. H. Gu, Signal Processing of Power Quality Disturbances, John Wiley \& Sons, 2006.

[11] F. Martin, Patterns of Enterprise Application Architecture, Addison-Wesley, 2002.

[12] W. W. Eckerson, "Three Tier client/server architecture: achieving scalability, performance, and efficiency in client server applications," Open Information Systems, vol. 10, no. 1, 1995. 


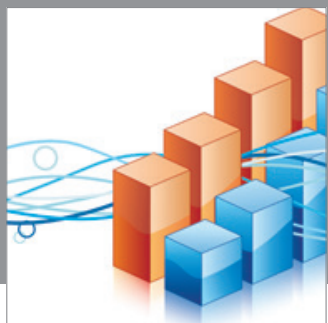

Advances in

Operations Research

mansans

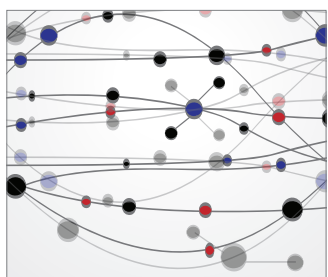

The Scientific World Journal
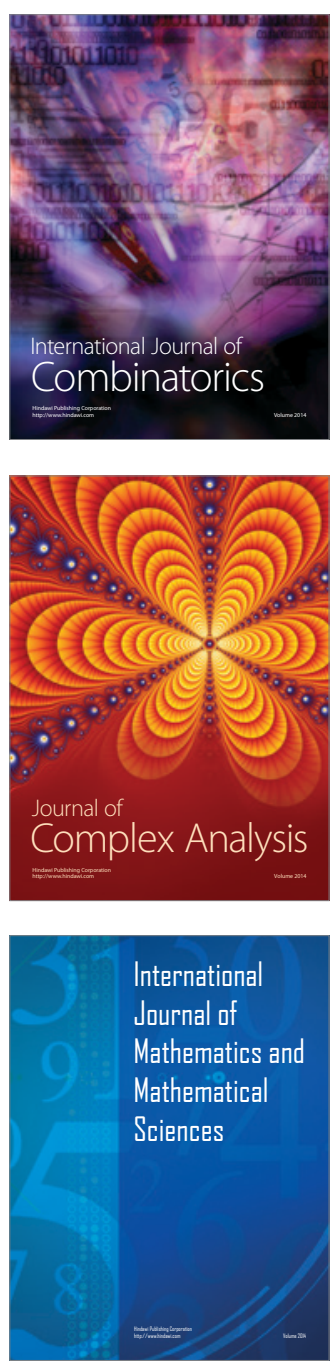
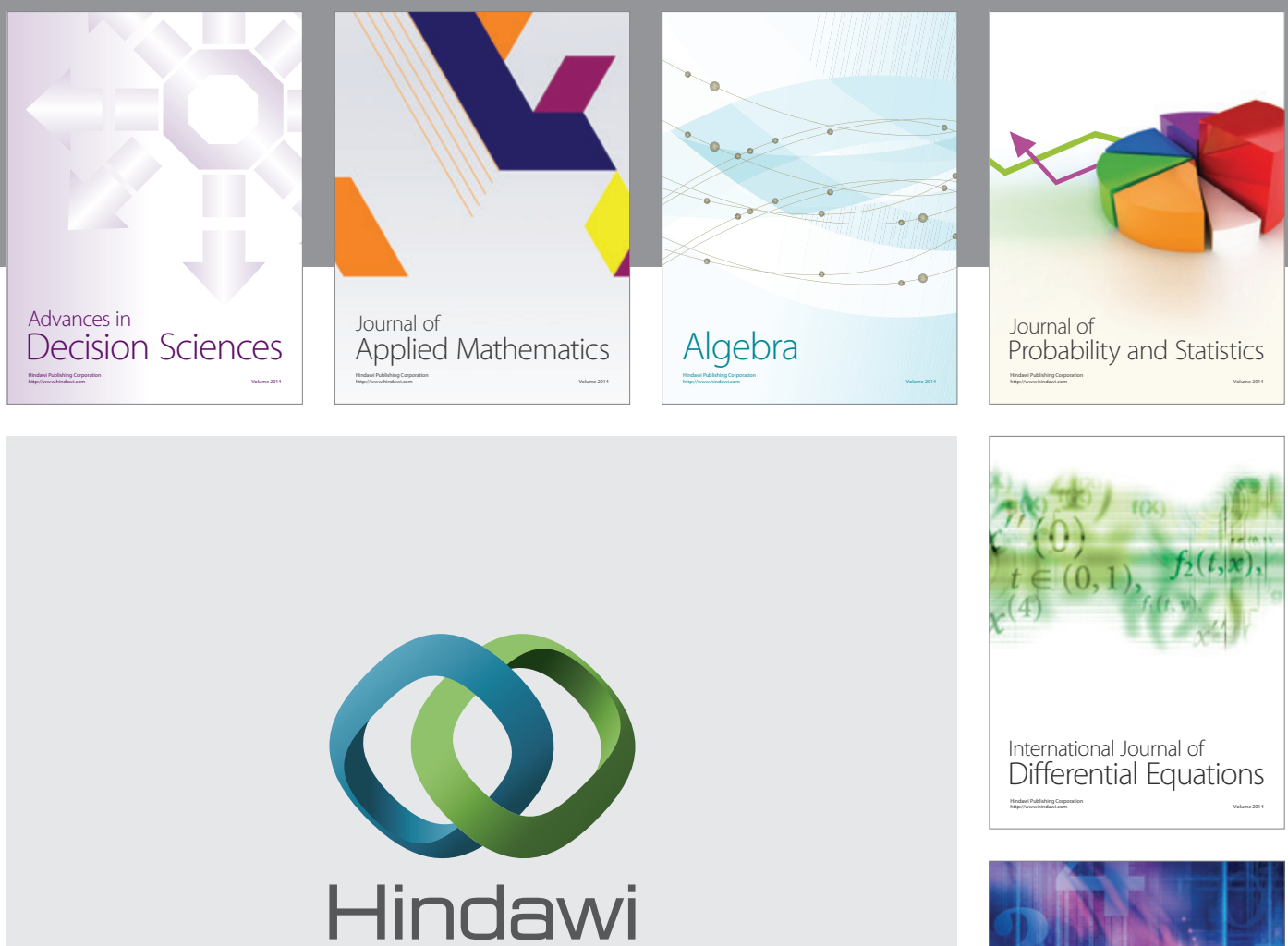

Submit your manuscripts at http://www.hindawi.com
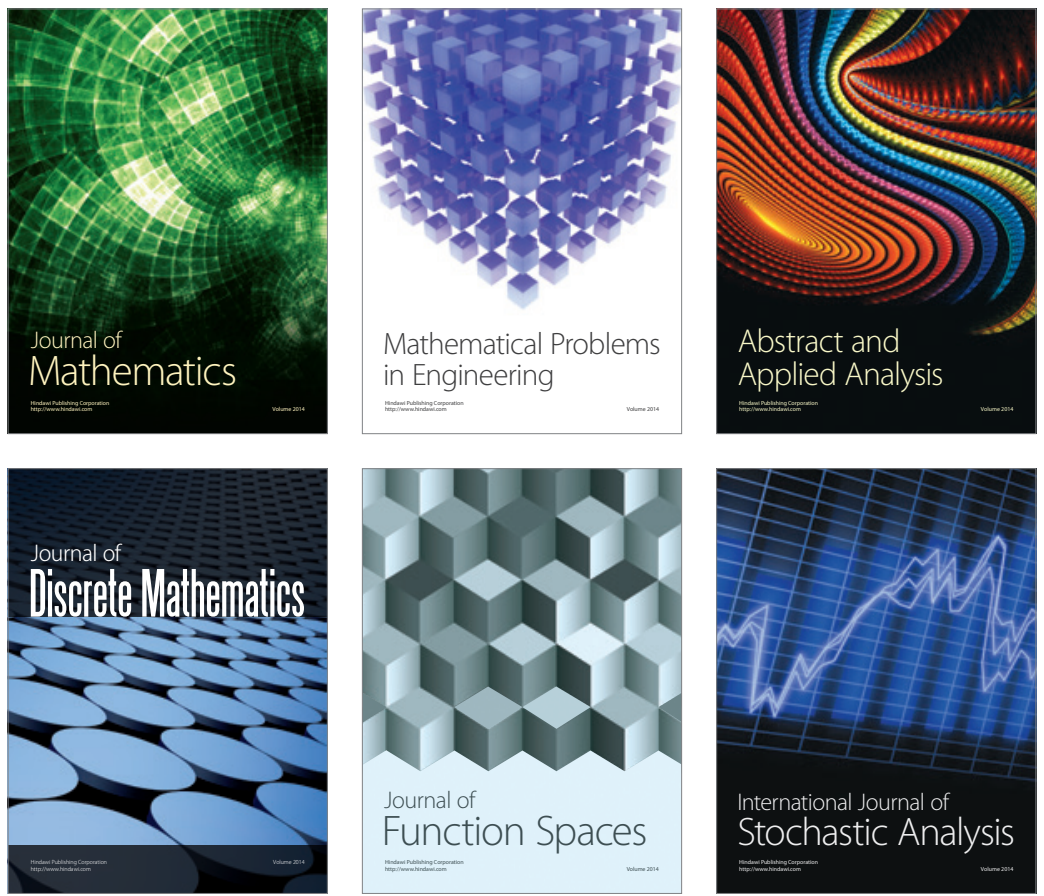

Journal of

Function Spaces

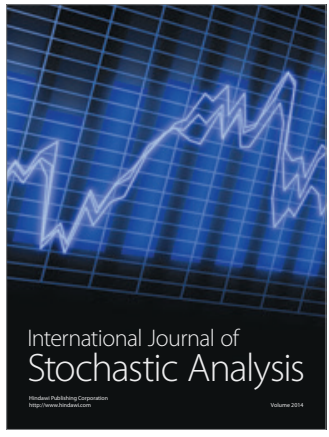

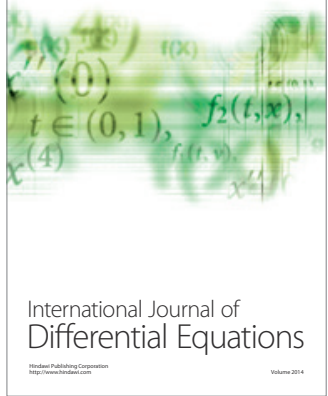
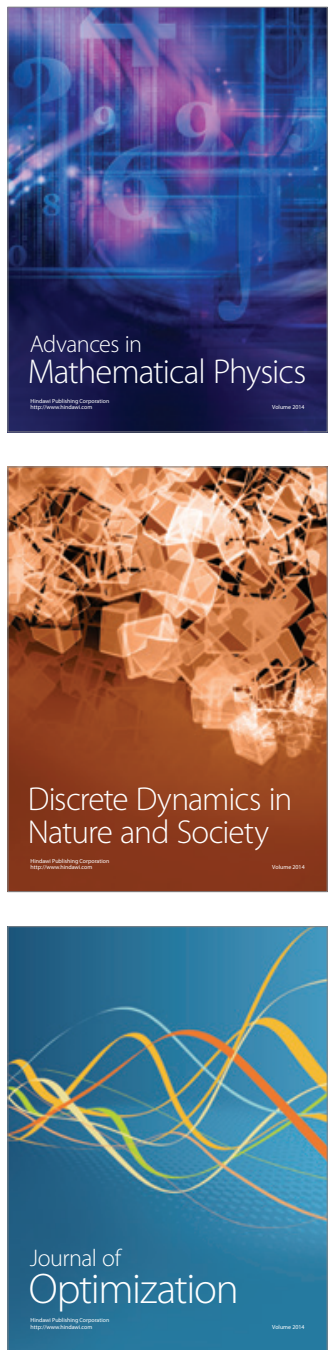